\title{
Humanitarian behavior across high-/low- context cultures: a comparative analysis between Switzerland and Colombia
}

\author{
Omid Alizadeh Afrouzi@
}

\begin{abstract}
The International Committee of the Red Cross (ICRC) attempts constantly to motivate its audience through social media to adopt humanitarian attitudes and behaviors. Owing to its multicultural audience, the results of this communicative attempt varies from region to region. In this context, in order to optimize the humanitarian communication outcome, it is of high importance to investigate the mediating role of culture. Drawing on Hall's context theory, this comparative survey-based study tries to analyze the influence of personal context culture on humanitarian behavior intention in a low-context-culture country (Switzerland) and a high-context-culture country (Colombia). The results indicated that once exposed to implicit social media posts of the ICRC, the Colombian showed slightly higher behavior intention compared to the Swiss and participants' personal context-culture score fully accounted for this difference. This study is also an empirical examination of Hall's context theory in a humanitarian communication context.
\end{abstract}

Keywords: Humanitarian communication, Context theory, Persuasion, ICRC, Red Cross, Humanitarian behavior, Colombia, Switzerland, Social media

\section{Introduction}

Since messages targeted at diverse audiences across the globe would have dissimilar impacts and are perceived differently, the international organizations are to adapt their messages to various cultural contexts rather than standardizing them (Hornikx and O'Keefe 2009: 41; La Ferle et al. 2008: 191).

Considered as one of the biggest sellers of humanitarian notions (Slim 2003: 12), the International Committee of the Red Cross (ICRC) deals also with various beneficiaries and needs to take into account the cultural elements in the daily communication with its multicultural audience.

According to Hall's context theory (Hall and Hall 1990; Hall 1976), different cultures have different ways of communicating; some communicate explicitly (low-

Correspondence: omid.alizadehafrouzi@student.unisg.ch

Swiss-Latin American Center, University of St.Gallen, Müller-Friedberg-Strasse 8, 9000 St.Gallen, Switzerland context culture) while others communicate implicitly (high-context culture). Individuals' cultural background affects how well they are capable of comprehending messages (Hall and Hall 1990: 7).

As the ICRC's messages are not always explicitly stated, the audience or "consumers of humanitarian messages" (Slim 2003: 8) will also comprehend them to different extents. That is, people from a low-context culture (LCC) are expected to have more difficulties in comprehending complex messages in comparison to those from a high-context culture (HCC) (Hornikx and Le Pair 2017: 1).

One of the main objectives of the ICRC is promoting humanitarian behaviors through persuasive communication and engaging the stakeholders (Daccord 2020). In this procedure, the humanitarian values are transferred through different types of channels and messages (Sala Rigler 2020). Nevertheless, humanitarian agencies are not always aware of the possible impacts of the way they

(c) The Author(s). 2021 Open Access This article is licensed under a Creative Commons Attribution 4.0 International License, which permits use, sharing, adaptation, distribution and reproduction in any medium or format, as long as you give appropriate credit to the original author(s) and the source, provide a link to the Creative Commons licence, and indicate if changes were made. The images or other third party material in this article are included in the article's Creative Commons licence, unless indicated otherwise in a credit line to the material. If material is not included in the article's Creative Commons licence and your intended use is not permitted by statutory regulation or exceeds the permitted use, you will need to obtain permission directly from the copyright holder. To view a copy of this licence, visit http://creativecommons.org/licenses/by/4.0/. 
communicate. In this sense, it is of high importance to understand to what extent the nationalities of individuals affect their humanitarian behavior intention.

Notwithstanding the great scholarly effort (Albouy 2017; Barrazaa et al. 2015; Ye et al. 2015; Kemp et al. 2013; EinGara and Levontin 2013) regarding persuasive communication and stakeholder's behavior intention in the context of humanitarianism, little attention (Winterich and Zhang 2014; Laufer et al. 2010) has been dedicated to the role of cultural difference in humanitarian persuasion.

Based on the above, this novel study attempts to analyze the mediating role of culture in the relationship between nationality and humanitarian behavior intention by focusing specifically on an LCC (Switzerland) and an HCC (Colombia). It is assumed that once exposed to implicit humanitarian messages of the ICRC, the Colombian show more behavior intention compared to the Swiss, and individuals' context-culture accounts for this difference. Previous findings (Hornikx and Le Pair 2017) have proved that this cultural difference leads to different comprehension levels of implicit messages.

The speedy development and spread of accessibility to Social Networking Sites (SNSs) have made persuasive communication even more complex, and the humanitarian messages are today more viral thanks to the new diffusion channels. In this sense, the present study seeks to address the issue at hand in a social media context and conduct the comparative analysis on the basis of two platforms of Facebook and Instagram, both used considerably by the ICRC.

In particular, the present research seeks to analyze the possible attitudinal effects of exposure to implicit humanitarian messages of the ICRC and examine whether the social media posts of the ICRC have different impacts across different cultures. Studies of this nature can increase the awareness of humanitarian agencies regarding the possible impacts of different ways they communicate with their beneficiaries. This research is also an empirical examination of Hall's context theory in humanitarian communication and thus enriches the limited literature in the field.

\section{Theoretical framework}

The theoretical framework that guides the present study is Edward Hall's model of low-context and high-context cultures (Hall and Hall 1990; Hall 1976) which is one of the dominant theoretical frameworks for interpreting intercultural communication.

According to Hall and Hall (1990): 6), "the cultures of the world can be compared on a scale from high to low context." Context, which means the information that surrounds an event, is a very important barrier in intercultural communication. "A high context communication or message is one in which most of the information is already in the person, while very little is in the coded, explicit, transmitted part of the message. While, a low context communication is just the opposite; the mass of the information is vested in the explicit code" (Hall 1976: 111).

Hall (1976) proposed that cultures can be identified based on the messages the members in a given culture prefer to use. In general, high-context communication employs indirect verbal expression and implication embedded in non-verbal communication and it is expected of the listener to figure out the meaning of the message taking into account the context. In contrast, low-context communication emphasizes direct and explicit information exchange and the audience does not have to take the complex context into account when decoding the message.

According to Hall and Hall (1990): 9), "high-context people are apt to become impatient and irritated when low-context people insist on giving them information they don't need. Conversely, low-context people are at a loss when high-context people do not provide enough information." One of the great communication challenges in life, argues Hall and Hall (1990): 9), is to find the appropriate level of contexting needed in each situation.

Based on Hall's classification (Hall and Hall 1990), toward the high end of the cultural context continuum are most Asians (Japan, China, and Korea), the Arabs, the Mediterranean peoples (Greece, Spain, and Italy), the Africans, and the South Americans, who "have extensive information networks among family, friends, colleagues, and clients and who are involved in close personal relationships," whereas at the low end of the continuum are North Americans, Germans, Swiss, Scandinavians, and other northern Europeans. For most normal transactions in daily life people in high-context cultures do not expect "much in depth, background information." In contrast, low-context people "compartmentalize their personal relationships, their work, and many aspects of day-to-day life; so, each time they interact with others they need detailed background information" (Hall and Hall 1990: 7).

Hall's influential model suggests that "individuals combine preprogrammed culture specific context and information to create meaning" (Kittler et al. 2011: 65). Within each culture, argues Hall and Hall (1990): 7), there are "specific individual differences in the need for contexting, the process of filling in background data." Since every person is influenced by the level of context, it is helpful to know whether the culture of a particular country falls on the high or low side of the scale. Furthermore, cultural communications are deeper and more complex than spoken or written messages. The essence of effective cross-cultural communication has more to 
do with releasing the right responses than with sending the "right" messages (Hall and Hall 1990: 30).

Since different cultures have different ways of communicating, international organizations, such as the ICRC, which are dealing with multicultural beneficiaries, should meet the growing need of adapting their communicative strategies to target cultures in order to improve the humanitarian communication outcome.

For the processing of implicit messages, the approach of context theory is highly relevant. As Hornikx and Le Pair (2017): 4) describe, "in HCCs people are said to prefer symbolic, artful language that is implicit. In LCCs, people are said to prefer explicit, task-related language." As a result, context theory predicts implicit messages to be better understood in high- rather than in low-context cultures.

Cultures cannot be classified as exclusively HCC or LCC, but some cultures tend to be at the higher end while others are at the lower end of the continuum (Hall 1976: 111). The terms HCC and LCC are not categorized with strict individual characteristics or boundaries, argues Yarn (2002); instead, many cultures tend to have a mixture or at least some concepts that are shared between them overlapping the two context cultures. In this regard, Gudykunst and Nishida (1986): 542) also acknowledge that "both low- and high-context communication are used in every culture, but (...) one tends to predominate."

Cardon (2008): 422) states that the context culture theory lacks empirical rigor since in this model contexting is most frequently discussed in terms of directness. To overcome this limitation and apply properly Hall's model, this study evaluates individually the Personal Context Culture (PCC) score of the Colombian and the Swiss proposed by Richardson and Smith (2007).

Drawing on Schwartz's perspective, Richardson and Smith (2007) argue that one cannot observe cultural values directly. "The commonalities in the intentional and unintentional value socialization to which different members of society are exposed reflect the cultural emphases that support and maintain the social, economic, and political system of the society" (Schwartz 1994: 92). Therefore, "the average of individual scores across members of a given culture should infer the prevailing value emphasized in that culture" (Richardson and Smith 2007: 481). Additionally, one should take into account that low-context and high-context values inside a culture are not necessarily consistent with each individual's use of HCC/LCC communication. As a result, researchers can analyze high-context and low-context communication at an individual level in order to explore highcontext and low-context values at a cultural level (Richardson and Smith 2007).
Measuring a cultural construct at the level of the studies' participants is an important methodological tool to enable attributing empirical, cultural differences to that cultural construct (Hoeken and Korzilius 2003: 294). Callow and Schiffman (2002): 274) indicate as well that it would be "advantageous to measure context at an individual (as opposed to a cultural) level." This measurement allows the author to first evaluate the applicability of Hall's model to this empirical research and then conduct the comparative analysis based on the same measurement.

Hall's context theory proved to be adequate in justifying the differences in comprehension of implicit messages (Hornikx and Le Pair 2017), yet this paper analyzes its pertinence to humanitarian behavior intention across countries with different cultural backgrounds.

\section{High-/low-context cultures and implicit messages}

The current study is an attempt to understand the relationship between LCC and HCC consumers of ICRC's humanitarian messages and their level of humanitarian behavior intention. To this end, their reaction to implicit messages will be analyzed. In order to distinguish between explicit and implicit messages, the present research takes advantage of the theory of independent continua proposed by Francisco Yus (1999).

Human beings have a wide range of linguistic choices to communicate their thoughts, ranging from the most explicit with less interpretive problems to the most implicit with more interpretive difficulties. In either case, as Yus (1999): 487) puts forward, "a certain percentage of success in human conversational interaction is the hearer's in supplying the missing elements in the speaker's utterance." This fact complements Hall's context theory.

Based on Yus' theory, instead of one continuum between two poles (one explicit and one implicit), the speaker's choice is, rather, between two sub-continua, one explicit and one implicit, and each of them with its own explicit-implicit gradation, that is, e-continuum for explicit communication and i-continuum for implicit communication.

The model of Yus emphasizes that "there are degrees of implicitness, ranging from the most implicit to the more-explicit-but-still-implicit information, inside the icontinuum" (Yus 1999: 493). In other words, as long as a message is not stated explicitly, it lays inside the icontinuum, with different levels of implicitness. This interpretation simplifies the distinction between explicit and implicit messages and helps to determine whether a humanitarian message of the ICRC is placed inside the e-continuum or the i-continuum. 
Human cognition is geared to the addressees' search for relevance in the in-coming (non)verbal stimuli that they process in the course of a conversational interaction. This search for relevance triggers the activation of hypotheses on the explicit or implicit quality of the stimulus which has to be processed, and constrains the eventual choice of a candidate to match the sender's intended interpretation (Sperber and Wilson 1986).

The complexity of a message can be the result of different message components (Lowrey 2008), such as the difficulty of the words that are used (e.g., jargon or words from a foreign language), the syntax of the sentences, or the length of the message. Hornikx and Le Pair (2017): 2) believe that "a message does not have one given complexity; what is complex to one person is not necessarily complex to another."

A communicative attempt proves to be successful once the recipients understand the message sent by a communicator. Thus, "communicators who wish to transmit information to a recipient are presumably motivated to construct their messages in a way that the recipient will understand and consider to be informative" (Wyer and Shrum 2015: 186).

The interpretation outlined above implies that information can be communicated implicitly or explicitly and that the more contextual assumptions which the hearer has to extract from contextual sources, the more the speaker has to count on the interlocutor for an optimal interpretive outcome.

Since the ICRC is targeting simultaneously a wide range of audience on social media by publishing contents with various humanitarian notions, there is a high probability of different comprehension levels throughout diverse cultural contexts. In this sense, along with the dual model of Yus (1999), this study builds the complexity of ICRC's humanitarian messages around the feature of implicitness (vs. explicitness).

\section{The ICRC and social media}

In an increasingly fragmented world, there are day by day more stakeholders for the ICRC to interact with and to influence in the frame of its humanitarian diplomacy. The advent of Social Networking Sites (SNSs) has provided the ICRC with new opportunities and challenges for its humanitarian horizon.

Regarding the importance of the digital presence of the ICRC, Maillot (2017): 11) asserts that "digital diplomacy has a huge impact on public advocacy, multilateral engagement, and acceptance of the ICRC's role and mandate by its stakeholders." The digital diplomacy has proven to be "a useful support to humanitarian diplomacy as it brings the ICRC and its stakeholders closer to the situation on the ground, while providing an immediate real-time sense of a situation by getting access to open sources of information provided by states and people living and facing conflict or disaster" (Maillot 2017: 11).

Just similar to many nonprofit organizations (Lovejoy and Saxton 2012), the humanitarian content that the ICRC publishes in different social media platforms can be generally divided into three categories: information, community, and action.

According to Lovejoy and Saxton (2012): 341), the first function of "information" involves spreading information about the organization, its activities, or anything of potential interest to followers. The second function of "community" taps into how organizations can foster relationships, create networks, and build communities. And the third function of "action" has as a central purpose getting followers to "do something" for the organization, whether it is to donate, buy a product, attend an event, join a movement, or launch a protest.

As Müller-Stewens et al. (2019): 67) state, the social media analytics has shifted from "nice-to-have to an essential issue" for the ICRC since gathering publicly available data on stakeholders and analyzing them contributes to important and useful results for the prosperity of the humanitarian movement.

For the ICRC, social media is not "a one waycommunication," yet a potential space to engage its stakeholders (Daccord 2020). That is, the digital presence of the ICRC on SNSs is more of interactive essence, rather than being solely dedicated to humanitarian informing. And in terms of cross-cultural communication, the ICRC takes advantage frequently of local communicators to communicate the humanitarian messages more efficiently to the target audience and improve the humanitarian persuasion outcome (Daccord 2020).

Based on the above and the increasing need to deal with humanitarian persuasion through social media, in this study, we try to analyze the feedbacks of audience from different cultural contexts to ICRC's social media content. Specifically, we focus on the "information" and "action" contents which are operative for the inquiries we propose in our study.

\section{Hypotheses}

Previous findings regarding the cross-cultural aspect of the communication testify that individuals from different context cultures vary in their reaction to complex and implicit messages. Basically, individuals from a higher context culture perceive implicit messages as less complex than individuals from a lower context culture (Hornikx and Le Pair 2017). The majority of studies drew their conclusions on the basis of groups of people: individuals from a country with a presumed lower context culture versus individuals from a country with a presumed higher context culture. 
As Cardon (2008) claims, the methodological approach of Hall is not unique. "The relationship between directness and contexting, based on traditional classifications of high-context and low-context cultures, is particularly tenuous" (Cardon 2008: 422). However, he acknowledges that "the fact that contexting has not been empirically validated should not necessarily be construed as a failure of the theory" (Cardon 2008: 422).

The present research analyzes on the basis of selfreported measurements the PCC score to evaluate individuals' level of context culture and verify the existing cultural difference in terms of high and low context. Although there are limitations associated with the use of self-reported measurements, it is currently the best existing tool (Matsumoto and Yoo 2006).

The main objective is to examine whether national differences in the humanitarian behavior intention after viewing ICRC's implicit posts can indeed be attributed to participants' PCC scores. Previous studies (Hornikx and Le Pair 2017) confirmed the difference in the perception of complex messages between HCC and LCC. If empirical support for the effect of context-cultures scores on the humanitarian behavior intention is to be found, it would considerably strengthen the notion of context culture as a perspective to study cultural differences and similarities in humanitarian communication.

Figure 1 visualizes the theoretical model of the role of context culture in the relationship between nationality and humanitarian behavior intention. First, it is assumed that participants from a higher context culture indeed score higher in terms of personal context culture compared to participants from a lower context culture.

H1: The Colombian score higher than the Swiss in terms of personal context culture (PCC).

The second hypothesis refers to the humanitarian behavior intention of the participants. Drawing on the higher message comprehension of the individuals from HCC, it is perceived that once exposed to implicit humanitarian messages of the ICRC, the participants from a higher context culture show more behavior intention.
H2: The Colombian show more behavior intention than the Swiss once exposed to the implicit messages of the ICRC.

The third hypothesis deals with the mediating role of the context culture in the relationship between the nationality and the behavior intention. It is assumed that the PCC score mediates this relationship.

\section{H3: Participants' personal context scores mediate the effect of nationality on humanitarian behavior intention.}

\section{Method}

\section{Participants}

A quantitative approach was deemed adequate for the purpose of this survey-based study. This research focuses on one European country (Switzerland) and one Latin American country (Colombia) which have rarely been compared in a humanitarian communication context. The main criteria for sample selection were cultural dimension (high vs. low) and active presence of the ICRC. The Red Cross conducts key operations and interacts with a wide range of beneficiaries both in Switzerland and Colombia ${ }^{1}$ which differ considerably in terms of contexting. Drawing on Hall's context theory (Hall 1976), Switzerland and Colombia are often regarded as being LCC and HCC, respectively (Kittler et al. 2011; Richardson and Smith 2007; Cardon 2008). In this paper, we follow the similar classification: Switzerland is expected to be a lower context culture than Colombia. Regardless of this general classification, we assess the individual context scores in sampled countries to verify empirically the cultural classification.

Overall, 170 respondents (Swiss, $n=73$; Colombian, $n$ =97) participated voluntarily in this comparative surveybased study. Taking into account the cultural diversity in sampled countries, especially Switzerland whose regions (German-speaking, French-speaking, and Italianspeaking regions) are differently ranked in terms of cultural context (Hofstede et al. 2010), the survey was distributed merely between the Swiss in German-speaking regions and the Colombian in Bogota and Medellin. The majority of respondents fell within the age range 21-30

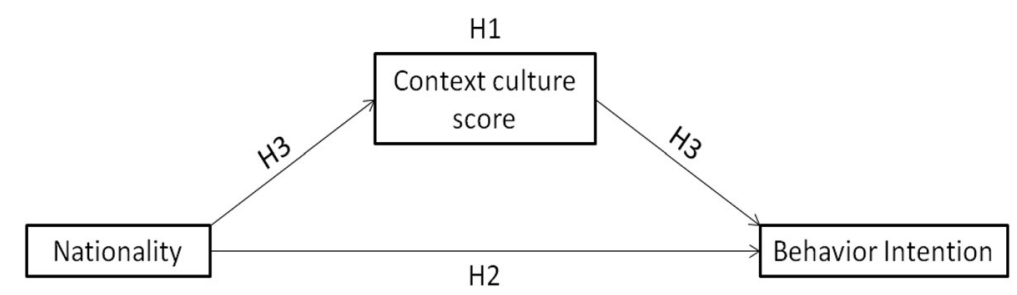

Fig. 1 Theoretical model of the role of context culture in humanitarian behavior intention (source: Elaboration of the author) 
years $(47.6 \%)$ with the second highest group in the category less than 20 years (18.8\%). Precisely, half of the total participants were female (50\%).

\section{Material}

In order to conduct a comprehensive analysis of the effect of context culture on humanitarian behavior intention, two implicit posts were selected from the Facebook and Instagram official pages of the ICRC. An implicit post refers to a post with different levels of verbal and non-verbal implicitness.

The ICRC has an active presence on different social media platforms: inter alia, Facebook, Instagram, Twitter, YouTube, and LinkedIn. In a humanitarian context, "deciding on your ideal platforms depends on your country and target audience" and you should meet your audience where they are (Lüge 2017). Facebook is by far the largest network and the mostly used SNS both in Switzerland and Colombia (Statcounter 2020a, 2020b). Social media scholars emphasize on the significance of cross-platform studies in comparison to single-platform studies (Rogers 2018). In other words, it is better to analyze a phenomenon across different SNSs, rather than one single platform. Therefore, Instagram was selected as the second platform to be used in this study because of its growing popularity in the world (Alhabash and Ma 2017) and the similarity between the objectives that the ICRC pursue with the use of Facebook and Instagram $^{2}$ (Sala Rigler 2020). Other criteria such as post format in terms of equal verbal and non-verbal content, as well as better access to data, were also considered.

For the purpose of providing participants with contents that varied in implicitness, two social media posts (Appendix 1) with distinct humanitarian ideas were selected. The Facebook post targeted donation behavior by informing about nutritional level in South Sudan and illustrating two hand palms insinuating a request. And the Instagram post dealt with the importance of aid workers' security by informing about this issue and depicting the bullet marks on an ambulance.

Due to the difference in presented humanitarian topics, and to avoid possible negative effects of this difference on participants' responses, the author determined taking any kind of humanitarian action regarding the specified issues (e.g., even sharing the post) as the aimed humanitarian behavior. Having this explanation in mind, the participants were asked to answer the questions about the humanitarian behavior intention after viewing each post.

\footnotetext{
${ }^{1}$ The list of countries where the ICRC conducts key operations is available at: https://www.icrc.org/en/where-we-work

${ }^{2}$ More information at: https://www.icrc.org/en/icrc-social-media
}

It is important to note that neither of the posts promoted explicitly the expected humanitarian behavior and both fell on the i-continuum proposed by Yus (1999). Regardless of the distinction between their verbal or non-verbal implicitness, this study focuses specifically on the reaction of the Colombian and the Swiss to ICRC's implicit social media content. As previously mentioned, humanitarian values are transferred through different messages (Sala Rigler 2020), but humanitarian agencies are not always aware of the possible impacts of the way they communicate.

This research had one-factor design. Social media posts with implicit humanitarian ideas were presented to participants with Swiss or Colombian nationality (between-subject design) and each of the respondents opined about the posts in the same order.

\section{Measure}

Measurement items for the survey were based upon and adapted from literature. Items for personal preference of high-/low-context culture were derived from Richardson and Smith (2007). In total, seven items with 5-point scale (mean reliability: $\alpha=.71$ ) were selected. Three examples of items were "It is more important to state a message efficiently than with great detail," "Intentions not explicitly stated can often be inferred from the context," and "A speaker can assume that listeners will know what they really mean" (all seven items are in Appendix 2).

The behavior intention items were derived from Ajzen (1991). Based on the Theory of Planned Behavior (TPB), respondents were to reply to four items with 5-point scale (mean reliability: Facebook: $\alpha=.72$; Instagram: $\alpha=$ .78) regarding behavioral beliefs, normative beliefs, control beliefs, and intention. The TPB is a theory that links one's beliefs and behavior. The theory states that intention toward attitude, subjective norms, and perceived behavioral control together shape an individual's behavioral intentions and behaviors (Ajzen 1991).

In terms of humanitarian behavior, once exposed to the humanitarian messages published by the ICRC, the audience may accept the humanitarian belief after being influenced by the message and acquire the intention. The extent to which the audience is persuaded is debatable, but are people from different cultural contexts affected similarly? In this sense, the role of cultural difference in the perception and acceptance of humanitarian messages gains more importance.

Two examples of the items regarding behavior intention were "For me to take an action regarding the poor in South Sudan on a regular basis is difficult/easy" and "For me to take an action regarding aid workers on a regular basis is valuable/worthless" (all four items for Facebook and Instagram are in Appendix 3). 
The questionnaire ended with items on nationality, gender, age, and education. The number of social media accounts and social media daily use were also questioned, but did not lead to any significant results.

\section{Procedure and statistical tests}

The survey was conducted over a period of 2 months (March 15-May 15, 2020). To evaluate the cultural difference between the Swiss and the Colombian according to Hall's context theory, this study compared the mean score of participants' PCC (H1).

Since the content of selected social media posts varied, for each respondent, a mean score for behavior intention was computed based on Facebook and Instagram post, individually. This separation also enabled the author to conduct a cross-platform analysis and compare the results. The mean scores for behavior intention were submitted to regression analyses for the direct effect of nationality on behavior intention $(\mathrm{H} 2)$.

For the indirect effects of nationality through PCC on behavior intention, the author used bootstrapping as mediation technique (H3). To do so, this study drew on the bootstrapping approach proposed by Hayes (2009).

\section{Results}

As a preliminary analysis, the author first tested whether Swiss participants scored lower on their PCC score than Colombian participants. This proved to be the case $(\mathrm{F}=$ $11,646, p=.001, \eta 2=.065)$. The Swiss participants had a lower context $\operatorname{score}^{3}(M=2.89, \mathrm{SD}=0.54, n=73)$ than the Colombian participants $(M=3.19, \mathrm{SD}=0.58, n$ $=.97)$. This result supports $\mathrm{H} 1$ and verifies the empirical efficiency of the classification proposed by Hall (1976). The effect size is relatively small, compared to Hall's classification, but this does not oppose the aim of the present study which focuses on the mediating role of PCC.

First of all, regarding the relationship between nationality and behavior intention, a linear regression showed that the nationality predicted the pertinent humanitarian behavior intention (Facebook: $\mathrm{F}=7,643, p=.006, R^{2}=$ $.044 ; B=.267, \mathrm{SE}=.097$; Instagram: $\mathrm{F}=20,903, p=$ $\left..000, R^{2}=.111 ; B=.486, \mathrm{SE}=.106\right)$ : the Colombian showed slightly higher behavior intention ${ }^{4}$ in both platforms (Facebook: $M=2.97, \mathrm{SD}=0.66$; Instagram: $M=$ $3.54, \mathrm{SD}=0.69$ ) in comparison to the Swiss (Facebook: $M=2.71, \mathrm{SD}=0.55$; Instagram: $M=3.05, \mathrm{SD}=0.66$ ). This result supports $\mathrm{H} 2$.

Multiple regression analyses were conducted to assess each component of the proposed mediation model. The mediation analysis showed also that nationality, as

\footnotetext{
${ }^{3}$ A lower score implies a lower context culture.

${ }^{4} \mathrm{~A}$ lower score implies a lower behavior intention.
}

mentioned above, was positively associated with behavior intention (Facebook: $B=.26, t=2.76, p=.006$; Instagram: $B=.48, t=4.57, p=.000$ ). It was also found that nationality was positively related to PCC (Facebook and Instagram: $B=.30, t=3.41, p=.000)$. Lastly, results indicated that the mediator, PCC, was positively associated with behavior intention (Facebook: $B=.22, t=2.75, p=$ .006; Instagram: $B=.21, t=2.38, p=.018$ ). Since both the a-path and b-path were significant for both posts, mediation analyses were tested using the bootstrapping method with bias-corrected confidence estimates (Preacher and Hayes 2004). In the present study, the 95\% confidence interval of the indirect effects was obtained with 50000 bootstrap resamples. Results of the mediation analysis confirmed the mediating role of PCC in the relationship between nationality and behavior intention (Facebook: $B=.06$, CI $[0.0079,0.1562]$; Instagram: $B=.06$, CI $[0.0017,0.1522])$. This result supports H3 for both platforms. However, it is important to note that the direct effect of nationality on behavior intention did not become non-significant (Facebook: $B=.19, t=$ 2.02, $p=.044$; Instagram: $B=.41, t=3.87, p=.002$ ) when controlling for PCC thus suggesting partial mediation. Figure 2 displays the results for both posts.

\section{Discussion and conclusion}

Although the use of direct and explicit messages in humanitarian communication is commonplace for an easier comprehension, the ICRC adheres sometimes to implicit messages on the SNSs to motivate its audience across the globe to take a specific humanitarian action or to follow a specific humanitarian attitude.

This study was an attempt to analyze the humanitarian behavior intention of the individuals after viewing ICRC's implicit messages and the effect of cultural difference on this process. In particular, drawing on Hall's high-/low-context theory (Hall 1976), our research examined the mediating role of the context culture in the relationship between nationality and humanitarian behavior intention.

To this aim, an LCC country (Switzerland) and an HCC country (Colombia) were selected as sampled nationalities. Furthermore, the analysis was conducted simultaneously along two social media platforms, Facebook and Instagram, by selecting one implicit post from each one. This distinction allowed the author to carry out also cross-platform comparison.

Effectively, several main conclusions can be taken from this study. It was revealed that the classification of high-/low-context proposed by Hall can be an effective measuring tool in cross-cultural research. The Swiss participants indeed scored lower than the Colombian ones in terms of PCC, thus reconfirming the applicability of Hall's classification in empirical research. 




Fig. 2 Results of regression analyses in the theoretical model (source: Elaboration of the author)

Although the effect size was relatively small, this did not oppose the objective of the study which addressed the mediating role of PCC. The small difference between the context culture of Swiss and Colombian participants in the study, compared to Hall's classification which places these nations on the extreme sides of the context continuum, can be as a consequence of the tendency of many cultures to have a mixture or at least some concepts that are shared between high- and low-context (Yarn 2002). Moreover, the world has become more connected through mobility and SNSs.

Even though context theory is an influential approach in addressing cultural differences and similarities in communication, this perspective has received very limited empirical attention (Cardon 2008; Kittler et al. 2011). The present research indicates that individuals' context scores, despite small differences, account for the national differences in terms of humanitarian behavior intention.

Moreover, the results showed that the nationality predicted the pertinent humanitarian behavior intention. In fact, the Colombian showed slightly higher behavior intention in both platforms in comparison to the Swiss. In order to find out the effect of cultural difference on their humanitarian behavior intention, a mediation model was proposed and put into multiple regression analyses. The indirect effect of nationality on behavior intention through participants' PCC proved to be significant. The results suggested the partial mediation of the culture in both platforms. Regarding the cross-platform analysis, no specific difference was observed in terms of behavior intention and the analysis of each platform showed similar results.

In conclusion, when it comes to implicit humanitarian messages, the humanitarian agencies, such as the ICRC, are to take into consideration the mediating role of culture and adapt their messages based on cultural factors to optimize the outcome of the persuasive communication.

It should be noted that the focus of this study was on the mediating role of culture in humanitarian communication. The future research should consider the potential roles of the participants' background, inter alia, humanitarian knowledge background, previous attitude toward the determined humanitarian behavior, and need for cognition (high/low). It is also important to incorporate senders' characteristics, such as source credibility and liking, in the research.

Regardless of the distinction between the verbal or non-verbal implicitness, this study concentrated on the reaction of the Colombian and the Swiss to ICRC's general implicit social media content. Scholars may delve more into the issue by distinguishing between the verbal and non-verbal cues and the importance of each factor in the process of humanitarian persuasion.

Future empirical studies may also consider other mediating and moderating variables in terms of message content, style, and structure features. Furthermore, message features, such as altruistic (vs. egoistic) appeals, gain (vs. loss) framing, and rhetorical troops, may be capable of neutralizing the mediating role of culture in humanitarian communication.

The samples of this study were selected from specific regions in Colombia (Bogota and Medellin) and Switzerland (German-speaking region). Since societies are becoming day by day more multicultural, it would be also essential to know how humanitarian behaviors change from one region with distinct cultural backgrounds to another, even within a country. Moreover, humanitarian scholars can investigate whether the active presence of the ICRC (or other humanitarian agencies) in a country, such as Colombia which has experienced years of internal armed conflict, can be a potential mediator/moderator of humanitarian behavior intention, in comparison to countries where the ICRC does not conduct key operations.

\section{Appendix 1}

The sampled social media posts

\section{Appendix 2}

Items of the context score scale (taken from Richardson and Smith 2007; a high score implies high-context culture) 
1. It is more important to state a message efficiently than with great detail.

2. Intentions not explicitly stated can often be inferred from the context.

3. A speaker can assume that listeners will know what they really mean.

4. People understand many things that are left unsaid.

5. Fewer words can often lead to better understanding.

6. You can often convey more information with fewer words.

7. Some ideas are better understood when left unsaid.

\section{Appendix 3}

Items of the behavior intention (taken from Ajzen 1991; a high score implies high behavior intention)

Facebook:

1. For me to take an action regarding the poor in South Sudan on a regular basis is difficult/easy.

2. I plan to take an action regarding the poor in South Sudan on a regular basis.

3. For me to take an action regarding the poor in South Sudan on a regular basis is valuable/ worthless.

4. It is expected of me that I take an action regarding the poor in South Sudan on a regular basis.

\section{Instagram:}

1. For me to take an action regarding aid workers on a regular basis is impossible/possible.

2. I will/will not make an effort to take an action regarding aid workers on a regular basis.

3. For me to take an action regarding aid workers on a regular basis is valuable/worthless.

4. It is expected of me that I take an action regarding aid workers on a regular basis.

\section{Acknowledgements}

I would like to express special appreciation and thanks to Professor Dr. Yvette Sánchez for all of her support and guidance during the writing of this paper. I am also indebted to the anonymous reviewers for their careful reading of my manuscript and their helpful comments.

\section{Author's contributions}

The author read and approved the final manuscript.

\section{Author's information}

Omid Alizadeh Afrouzi is a PhD candidate at Swiss-Latin American Center at the University of St. Gallen. The main areas of his research are humanitarian communication, persuasive communication, and discourse studies. He is currently the beneficiary of Swiss Government Excellence Scholarship (ESKAS).

\section{Funding}

The author received no financial support for the research, authorship, and publication of this article.

\section{Availability of data and materials}

The datasets used and/or analyzed during the current study are available from the corresponding author on reasonable request.

\section{Competing interests}

The author declares no competing interests.

Received: 3 August 2020 Accepted: 10 December 2020

Published online: 04 January 2021

\section{References}

Ajzen I (1991) The theory of planned behavior. Organizational Behavior Human Decision Process 50(2):179-211. https://doi.org/10.1016/0749-5978(91)90020-T

Albouy J (2017) Emotions and prosocial behaviours: a study of the effectiveness of shocking charity campaigns. Recherche et Applications en Marketing (English edition) 32(2):4-25. https://doi.org/10.1177/2051570716689241

Alhabash S, Ma M (2017) A tale of four latforms: motivations and uses of Facebook, Twitter, Instagram, and Snapchat among college students? SOCIAL MEDIA + SOCIETY 3(1). doi: https://doi.org/10.1177/2056305117691544.

Barrazaa JA, Alexander V, Beavina LE, Terrisa ET, Zakab PJ (2015) The heart of the story: peripheral physiology during narrative exposure predicts charitable giving. Biological Psychology 105:138-143. https://doi.org/10.1016/j. biopsycho.2015.01.008

Callow M, Schiffman LG (2002) Implicit meaning in visual print advertisements: a cross-cultural examination of the contextual communication effect. Int J Advertising 21(2):259-277. https://doi.org/10.1080/02650487.2002.11104929

Cardon PW (2008) A critique of Hall's contexting model: a meta-analysis of literature on intercultural business and technical communication. J Business Technical Communication 22(4):399-428. doi: https://doi.org/10.1177/ 1050651908320361

Daccord Y (2020) Exclusive interview with the director general of the International Committee of the Red Cross. (O. Alizadeh Afrouzi, Interviewer).

Ein-Gara D, Levontin L (2013) Giving from a distance: putting the charitable organization at the center of the donation appeal. J Consumer Psychol 23(2): 197-211. https://doi.org/10.1016/j.jcps.2012.09.002

Gudykunst WB, Nishida T (1986) Attributional confidence in low- and highcontext cultures. Human Communication Research 12:525-549. https://doi. org/10.1111/j.1468-2958.1986.tb00090.x

Hall ET (1976) Beyond culture. Doubleday, New York

Hall ET, Hall MR (1990) Understanding cultural differences: Germans, French and Americans. Intercultural Press, Yarmouth, England.

Hayes AF (2009) Beyond Baron and Kenny: statistical mediation analysis in the new millennium. Communication Monographs 76(4):408-420. https://doi. org/10.1080/03637750903310360

Hoeken H, Korzilius H (2003) Conducting experiments on cultural aspects of document design: why and how? Communications 28(3):285-304. https:// doi.org/10.1515/comm.2003.018

Hofstede G, Hofstede GJ, Minkov M (2010) Cultures and organizations - software of the mind: intercultural cooperation and its importance for survival. McGraw Hill, New York

Hornikx J, Le Pair R (2017) The influence of high-/low-context culture on perceived ad complexity and liking. J Global Marketing 30(4):228-237. https://doi.org/10.1080/08911762.2017.1296985

Hornikx J, O'Keefe DJ (2009) Adapting consumer advertising appeals to cultural values a meta-analytic review of effects on persuasiveness and ad liking. Ann Int Communication Assoc 33(1):38-71. https://doi.org/10.1080/23808985. 2009.11679084

Kemp E, Kennett-Hensel PA, Kees J (2013) Pulling on the heartstrings: examining the effects of emotions and gender in persuasive appeals. J Advertising 42(1):69-79. https://doi.org/10.1080/00913367.2012.749084

Kittler MG, Rygl D, Mackinnon A (2011) Special review article: beyond culture or beyond control? Reviewing the use of Hall's high-/low-context concept. Int J Cross Cultural Management 11(1):63-82. https://doi.org/10.1177/ 1470595811398797

La Ferle C, Edwards SM, Lee WN (2008) Culture, attitudes, and media patterns in China, Taiwan, and the U.S.: balancing standardization and localization decisions. J Global Marketing 21(3):191-205. https://doi.org/10.1080/ 08911760802152017

Laufer D, Silvera DH, McBride JB, Schertzer SM (2010) Communicating charity successes across cultures: highlighting individual or collective achievement? 
Eur J Marketing 44(9/10):1322-1333. https://doi.org/10.1108/ 03090561011062862

Lovejoy K, Saxton, GD (2012) Information, community, and action: how nonprofit organizations use social media. J Computer-Mediated Communication 13(3): 337-353. doi: https://doi.org/10.1111/j.1083-6101.2012.01576.x.

Lowrey TM (2008) The case for a complexity continuum. In: McQuarrie EF, Phillips BJ (eds) Go figure: new directions in advertising rhetoric. M.E. Sharpe, Armonk, pp 159-177

Lüge T (2017) How to use social media to engage with people affected by crisis. ICRC, IFRC, and UNOCHA. Retrieved from: https://www.icrc.org/en/ document/social-media-to-engage-with-affected-people.

Maillot A (2017) Digital diplomacy and the ICRC: scope and relevance for humanitarian diplomacy. DiploFoundation Policy Papers and Briefs 7.

Matsumoto D, Yoo SH (2006) Toward a new generation of cross-cultural research. Perspect Psychol Sci 1(3):234-250. https://doi.org/10.1111/j.1745-6916.2006. 00014.x

Müller-Stewens G, Dinh T, Hartmann B, Eppler M, Bünzli F (2019) The professionalization of humanitarian organizations: the art of balancing multiple stakeholder interests at the ICRC. Springer, St. Gallen

Preacher KJ, Hayes AF (2004) SPSS and SAS procedures for estimating indirect effects in simple mediation models. Behavior Research Methods Instruments Computers 36(4):717-731. https://doi.org/10.3758/BF03206553

Richardson RM, Smith SW (2007) The influence of high/low-context culture and power distance on choice of communication media: students' media choice to communicate with Professors in Japan and America. Int J Intercultural Relations 31(4):479-501. doi: https://doi.org/10.1016/j.jijntrel.2007.01.002.

Rogers R (2018) Digital methods for cross-platform analysis. In: Burgess J, Marwick A, Poell T (eds) . The SAGE handbook of social media. SAGE Publications, United States of America, pp 91-110

Sala Rigler G (2020) Entrevista exclusiva con la responsable del servicio digital de Comité Internacional de la Cruz Roja (CICR) en América Latina. (O. Alizadeh Afrouzi, Interviewer).

Schwartz SH (1994) Beyond individualism/collectivism: new cultural dimensions of values, In: Book Editor (Ed.), Individualism and collectivism: theory, method, and applications. Sage, Thousand Oaks, pp 85-119.

Slim H (2003) Marketing humanitarian space: argument and method in humanitarian persuasion. Centre for Humanitarian Dialogue (HD Centre)

Sperber D, Wilson D (1986) Relevance: communication and cognition. Blackwell, Oxford

Statcounter (2020a) Social media stats Colombia. Retrieved November 7, 2020, from Statcounter: https://gs.statcounter.com/social-media-stats/all/colombia.

Statcounter (2020b) Social media stats Switzerland. Retrieved November 7, 2020, from Statcounter: https://gs.statcounter.com/social-media-stats/all/ switzerland.

Winterich KP, Zhang Y (2014) Accepting inequality deters responsibility: how power distance decreases charitable behavior. J Consumer Res 41(2):274-293. https://doi.org/10.1086/675927

Wyer RS, Shrum LJ (2015) The role of comprehension processes in communication and persuasion. Media Psychology 18(2):163-195. https://doi. org/10.1080/15213269.2014.912584

Yarn D (2002) Dictionary of conflict resolution. Jossey-Bass, Michigan

Ye N, Teng L, Yu Y, Wang Y (2015) "What's in it for me?": the effect of donation outcomes on donation behavior. J Business Res 68(3):480-486. https://doi org/10.1016/j.jbusres.2014.09.015

Yus F (1999) Misunderstandings and explicit/implicit communication. Pragmatics 9(4):487-517. https://doi.org/10.1075/prag.9.4.01yus

\section{Publisher's Note}

Springer Nature remains neutral with regard to jurisdictional claims in published maps and institutional affiliations.

\section{Submit your manuscript to a SpringerOpen ${ }^{\circ}$ journal and benefit from:}

- Convenient online submission

- Rigorous peer review

- Open access: articles freely available online

High visibility within the field

- Retaining the copyright to your article

Submit your next manuscript at $\boldsymbol{\nabla}$ springeropen.com 